\title{
CD47 overexpression is associated with decreased neutrophil apoptosis/ phagocytosis and poor prognosis in non-small-cell lung cancer patients
}

Lourdes Barrera ${ }^{1,2}$, Edgar Montes-Servín ${ }^{1}$, Juan-Manuel Hernandez-Martinez ${ }^{1,3}$, María de los Ángeles García-Vicente ${ }^{1}$, Elizabeth Montes-Servín ${ }^{1}$, Marytere Herrera-Martínez ${ }^{1}$, José C Crispín ${ }^{4}$, José Rafael Borbolla-Escoboza ${ }^{5}$ and Oscar Arrieta*,1

${ }^{1}$ Functional Unit of Thoracic Oncology and Laboratory of Personalized Medicine, Instituto Nacional de Cancerología, Mexico City, Mexico; ${ }^{2}$ Global Product and Portfolio Strategy, Oncology, AstraZeneca, Gaithersburg, MD, USA; ${ }^{3}$ CONACYT-Instituto Nacional de Cancerología, Mexico City, Mexico; ${ }^{4}$ Department of Immunology and Rheumatology, Instituto Nacional de Ciencias Médicas y Nutrición Salvador Zubirán, Mexico City, Mexico and ${ }^{5}$ Medical Affairs, Oncology, AstraZeneca, Luton, UK

Background: Non-small-cell lung cancer (NSCLC) patients often exhibit neutrophilia, which has been associated with poor clinical outcomes. However, the mechanisms that lead to neutrophilia have not been fully established. CD47 is an antiphagocytic molecule that promotes neutrophil recruitment.

Methods: Blood was collected from 50 treatment-naive patients with advanced NSCLC and from 25 healthy subjects. The frequency of $\mathrm{CD}_{6} 6 \mathrm{~b}^{+}$cells and the expression of CD47 were determined by flow cytometry. Neutrophil apoptosis was determined by 7-amino-actinomycin D/Annexin V-APC staining. Phagocytosis was assessed by flow cytometry. Reactive oxygen species production after phorbol 12-myristate 13-acetate treatment was quantified by $2^{\prime}, 7^{\prime}$-dichlorofluorescein fluorescence. Proinflammatory plasma cytokines were quantified using a cytometric bead array assay.

Results: The percentage of circulating neutrophils was significantly higher in patients than in controls $(P<0.001)$. Patient-derived neutrophils had a higher oxidative potential than those of controls $(P=0.0286)$. The number of neutrophils in late apoptosis/ necrosis was lower in patients than in controls $(P=0.0317)$. Caspase $3 / 7$ activation was also lower in patients than in controls $(P=0.0079)$. CD47 expression in whole-blood samples and in the neutrophil fraction was higher in NSCLC patients than in controls $(P=0.0408$ and $P<0.001)$. Patient-derived neutrophils were phagocytosed at a lower rate than those of controls $(P=0.0445)$. CD47 expression in neutrophils negatively correlated with their ingestion by macrophages $(P=0.0039)$. High $C D 47$ expression was associated with a lower overall survival.

Conclusions: Increased CD47 expression on the surface of neutrophils was associated with a delay in neutrophil apoptosis and with an impairment in their phagocytic clearance by macrophages, suggesting that CD47 overexpression may be one of the underlying mechanisms leading to neutrophilia in NSCLC patients.

*Correspondence: Dr O Arrieta; E-mail: ogar@unam.mx

Received 3 April 2017; revised 18 April 2017; accepted 19 May 2017; published online 20 June 2017

(C) 2017 Cancer Research UK. All rights reserved 0007-0920/17 
Lung cancer remains the leading cause of cancer death worldwide (Arrieta et al, 2013) and the second most common cancer among both men and women (Global Burden of Disease Cancer et al, 2017). The majority of patients are diagnosed with advanced-stage disease, and despite technological advancements on all fronts of clinical practice, the prognosis for patients with lung cancer remains dismal (Arrieta et al, 2013). Haematologic abnormalities, including anaemia, thrombocytosis and leukocytosis are frequently observed in lung cancer patients. Although neutrophilic leukocytosis (also known as neutrophilia) has long been reported in patients with lung cancer, the underlying mechanisms leading to this condition have not been fully elucidated.

Acute inflammation is a physiological process through which the innate immune system responds to irritation, injury and infection. If unresolved, acute lung inflammation can progress to chronic inflammation, which has been directly implicated in a wide range of lung diseases such as acute respiratory distress syndrome, asthma, cystic fibrosis, chronic obstructive pulmonary disease, emphysema and lung cancer (Robb et al, 2016). Neutrophils are undoubtedly major effectors of acute and chronic inflammation. Consequently, a common feature between these diseases is chronic neutrophilic inflammation, as evidenced by an exacerbated and sustained infiltration of neutrophils into the lungs with concurrent neutrophilic leukocytosis (Gernez et al, 2010, Anand and Anand, 2012).

In patients with non-small-cell lung cancer (NSCLC), there is a strong correlation between poor clinical outcomes and high neutrophil content, both locally (Ilie et al, 2012) and systemic (Arrieta et al, 2010; Sanchez-Lara et al, 2012; Carus et al, 2013; Gu et al, 2015; Peng et al, 2015; Yin et al, 2015), suggesting that neutrophils and inflammation have an important role during carcinogenesis.

Owing to their pro-inflammatory functions and potential toxicity against host tissue, neutrophil numbers are tightly regulated through a fine balance between their production, retention, mobilisation, margination and clearance from the system (Silvestre-Roig et al, 2016). Therefore, the successful resolution of inflammation involves the cessation of further neutrophil recruitment, the induction of neutrophils to undergo programmed cell death as well as the phagocytic clearance of dying cells (Serhan and Savill, 2005; Mora-Jensen et al, 2011).

Healthy cells are protected from phagocytosis by displaying anti-phagocytosis molecules such as CD31, CD200, plasminogen activator inhibitor 1 and the integrin-associated protein/CD47 (Gitik et al, 2014). CD47 is expressed on the surface of many cells types but it is particularly abundant on red blood cells (RBCs) and leukocytes (Oldenborg et al, 2000). Binding of CD47 to its macrophage receptor, signal regulatory protein alpha (SIRP- $\alpha$ ), initiates a signal transduction cascade that results in the inhibition of phagocytosis (Oldenborg et al, 2001). Conversely, in cells undergoing apoptosis, CD47 expression is reduced and phagocytosis increased. Under this setting, CD47 can also be redistributed into patches distant from the phagocytic synapse.

It has been shown that various types of human tumours upregulate the expression of CD47 as a mechanism to avoid immune-mediated elimination (Goto et al, 2014). Recently, it has been show that CD47 expression in NSCLC specimens and cell lines correlates with clinical staging, lymph node metastasis and distant metastasis (Zhao et al, 2016).

CD47 supports the migration of neutrophils and activated T cells to the sites of infection via its interactions with SIRP- $\alpha$, SIRP- $\gamma$ and a subset of integrins (Liu et al, 2001, 2002; Azcutia et al, 2012), which indicates that CD47 expression on neutrophils, leukocytes and endothelium is critical for these immune cells to localise to sites of inflammation. Furthermore, neutrophils can be eliminated by the blockade of the anti-phagocytic signal CD47 (Majeti et al, 2009; Chao et al, 2011).
It is thus possible that changes in the expression of CD47 (which reportedly affect the accumulation and clearance of neutrophils from the system) could underlie, at least in part, the neutrophilia observed in patients with NSCLC. The aim of this study was to evaluate the expression of CD47 in circulating neutrophils, to associate this expression with clinical characteristics and prognosis in patients with advanced NSCLC and finally, to evaluate the phenotype, apoptosis, activation state, reactive oxygen species (ROS) production and inflammatory cytokines between patients with NSCLC and healthy subjects.

\section{MATERIALS AND METHODS}

Study design. A total of 50 patients with NSCLC in stage IIIB and IV were enrolled from January to December 2013 at the National Institute of Cancer in Mexico. All patients signed an informed consent document that was approved by the Institutional Review Board and Ethics Committee (INCAN (013/020/ICI) (CV773/13)) from the National Institute of Cancer. The inclusion criteria were as follows: adult patients ( $>18$ years); newly diagnosed, disease stage IIIB or IV; histopathological confirmation of NSCLC; Eastern Cooperative Oncology Group (ECOG) status of 0-2; free of any treatment (radiation, chemotherapy or immunotherapy) and eligible to receive chemotherapy (carboplatin-taxol) at the time of diagnosis; and no history of autoimmune disease or of recent steroid therapy. Standard clinicopathological characteristics (age, sex, smoking history, wood-smoke exposure, BMI, metastases, oligometastases, central nervous system (CNS) metastases, pleural effusion, history of diabetes mellitus and hypertension) were recorded from patients at the time of diagnosis. Blood samples of healthy subjects $(N=25)$, paired by age and gender, were obtained from the Blood Transfusion Center bank, and information concerning smoking history, wood-smoke exposure and comorbidities was recorded. Detailed characteristics of the patients can be found in Supplementary Table 1.

Sample collection. A volume of $16 \mathrm{ml}$ of blood was drawn into two $8 \mathrm{ml}$ EDTA tubes (BD Biosciences, San Jose, CA, USA) from patients and healthy subjects. One milliliter of blood was used for fresh whole-blood immunofluorescence staining and analysed by flow cytometry. Seven milliliter were centrifuged, the plasma was collected and stored at $-80^{\circ} \mathrm{C}$ for subsequent cytokine analysis. Eight milliliter were used for neutrophil isolation and functional assays.

Phenotypic characterisation by flow cytometry. Phenotypic characterisation and activation state assessment of neutrophils were performed by flow cytometry analyses according to the standard protocols. In brief, antibodies were added to $100 \mu \mathrm{l}$ of fresh whole blood and incubated in the dark for $15 \mathrm{~min}$ at room temperature. Afterwards, red blood cells were lysed using RBC lysis buffer $1 \times$ and cells were washed twice with cell staining buffer. Cells were then acquired and analysed. The following combination of monoclonal antibodies was used: anti-CD66b-PerCp Cy5.5 (G10F5); and anti-CD47-FITC (CC2C6) (Biolegend, San Diego, CA, USA). Fluorescence Minus One (FMO) negative controls correspond to samples stained with all the fluorescent conjugates, minus the one being tested. Gates were set using fluorescence minus one. All antibodies were used according to the manufacturers' instructions. Finally, samples were acquired in a FACS Aria II Flow Cytometer (BD Biosciences) and analysed with FlowJo software 10.1 (Tree Star, Ashland, OR, USA). The leukocyte population was gated based on morphological parameters on a forward $v s$ side scatter (FSC/SSC) plot. Neutrophils were defined as $\mathrm{CD} 6 \mathrm{~b}^{+}$. The mean fluorescence intensity (MFI) was calculated by FACS Aria II and was used to present the expression levels of CD47 molecules on the membrane of neutrophils in this study. 
Cytokine quantification. Plasma levels of the cytokines and chemokines IL-8, IL-2, IL-17A, IFN- $\gamma$, IL-4, IL-1 $\beta$, IL-6, IL-10, IL-12p70 and TNF were quantified using a Pro-Inflammatory and Th1/Th2/Th17cytometric bead array assay kit (BD Biosciences, Mexico City, Mexico) according to the manufacturer's instructions. Samples were acquired using a FACS Aria II Flow Cytometer (BD Biosciences) and analysed with FCAP Array Software V. 3.0 (Soft Flow, Pecs, Hungary).

Neutrophil isolation. Eight millilitre blood samples of healthy subjects and patients were diluted in PBS at a ratio of $1: 1 \mathrm{v} / \mathrm{v}$ before separation by density gradient centrifugation (Polymorphprep, AXIS-SHIELD PoC AS, Oslo, Norway). The interphase contains mononuclear cells and polymorphonuclear leukocytes (PMNs). The purity and viability of PMNs isolated using this method were within acceptable parameters (higher than 90\%). Recovered neutrophils were gown in propylene tubes or 24-well microplates in RPMI 1640 medium supplemented with 10\% FBS at $37^{\circ} \mathrm{C}, 5 \% \mathrm{CO}_{2}$ for $24 \mathrm{~h}$ after which functional assays (apoptosis and phagocytosis) were performed.

Caspase activation and apoptosis. Polymorphonuclear leukocytes $\left(2 \times 10^{6}\right.$ cells $)$ were grown in RPMI for $24 \mathrm{~h}$, after which caspase activation and spontaneous apoptosis was evaluated. An antiCD66b monoclonal antibody was used to identify neutrophilspecific populations. The activity of caspases 3 and 7 was evaluated with the CellEvent Kit Caspase-3/7 Green Detection Reagent (Life Technologies, Eugene, OR, USA). Polymorphonuclear leukocytes $\left(2 \times 10^{6}\right.$ cells $)$ were grown in RPMI for $24 \mathrm{~h}$, after which cells were incubated for $30 \mathrm{~min}$ at $37^{\circ} \mathrm{C}$ with $5 \mu \mathrm{m} \mathrm{ml}^{-1}$ of Green Detection Reagent. Samples were then observed under a microscope FLoid Cell Imaging Station (Life Technologies) with a $\times 20$ objective. Micrographs from five randomly selected fields were taken for each sample. Positive cells were counted and the data were analysed with Image J Software 1.49 (NIH, Bethesda, MD, USA).

Apoptosis of PMN was determined using the Annexin V-APC apoptosis detection kit (BD Biosciences) according to the manufacturer's protocol. Briefly, $24 \mathrm{~h}$ after plating, cells were incubated with an anti-CD66b mAb for $15 \mathrm{~min}$ and washed $(2 \times)$ with cold cell staining buffer. Cells were then re-suspended in Annexin V Binding Buffer. Samples were then stained with $5 \mu \mathrm{l}$ of Annexin V-APC and $2.5 \mu \mathrm{l}$ of 7-amino-actinomycin D (7-AAD) solution for $15 \mathrm{~min}$ at room temperature $\left(25^{\circ} \mathrm{C}\right)$ in the dark. Additional Annexin V Binding Buffer was added to each tube. Cells were analysed on a FACS Aria II Flow Cytometer (BD Biosciences) and analysed with FlowJo software 10.1 (Tree Star). Excitation was set at $488 \mathrm{~nm}$, and 7-AAD fluorescence was detected at $650 \mathrm{~nm}$ long-pass filter.

Cell culture and THP-1 differentiation to macrophages. The THP-1 cell line was obtained from ATCC (TIB-202), and maintained at $2 \times 10^{5}$ cells per $\mathrm{ml}$ in RPMI 1640 medium supplemented with $10 \%$ FCS and $2 \mu \mathrm{Ml}^{-1}$ L-glutamine. A total of $2 \times 10^{6}$ THP- 1 cells per $\mathrm{ml}$ were differentiated using $200 \mathrm{~nm}$ phorbol 12-myristate 13-acetate (PMA, Sigma-Aldrich, St Louis, MO, USA) for $72 \mathrm{~h}$. Differentiation of PMA-treated cells was enhanced by changing the PMA-containing media $72 \mathrm{~h}$ after the initial treatment with fresh RPMI 1640 (10\% FCS and 1\% Lglutamine) for 5 additional days.

Phagocytosis. Blood samples from five patients and four healthy subjects were used for neutrophil isolation. One fraction of PMNs was used to determine CD47 expression and another fraction was resuspended in PBS and labelled with $10 \mu \mathrm{M}$ CellTracker Green (5chloromethyfluorescein; CMFDA, Invitrogen, Waktham, MA, USA.) for $30 \mathrm{~min}, 37^{\circ} \mathrm{C}$. The CMFDA-labelled PMNs were incubated in RPMI in round-bottom polypropylene tubes at $37^{\circ} \mathrm{C}, 5 \% \mathrm{CO}_{2}$ for $24 \mathrm{~h}$, to induce spontaneous apoptosis. Differentiated THP-1 macrophages were co-cultured with
CMFDA-labelled PMNs at a ratio of 5:1 (PMN to MDM) for $4 \mathrm{~h}$ at $37^{\circ} \mathrm{C}, 5 \% \mathrm{CO}_{2}$. For each condition, cells were stained with anti-CD66b to exclude eosinophils from the analysis. Macrophages were detached and analysed by flow cytometry as follows: macrophages were distinguished by their typical high FSC characteristics. A minimum of 10000 CD66b-negative events were acquired. Macrophages that had ingested CMFDA-labelled apoptotic neutrophils became BL1-positive. To determine the phagocytic index, the total number of the THP-1 events acquired was divided by the number of CMFDA-positive THP-1 within the CD66b-negative gate. Flow cytometric analysis was performed with FlowJo software, version 10.1 (Tree Star).

Reactive oxygen species production. The production of ROS was measured by membrane permeable $2^{\prime}-7^{\prime}$-dichlorofluorescin diacetate $\left(\mathrm{H}_{2} \mathrm{DCFDA}\right.$; Life Technologies Inc., Catalogue No. D-399), which is oxidised to fluorescent $2^{\prime}, 7^{\prime}$-dichlorofluorescein (DCF) by ROS following cleavage of its acetate groups by intracellular esterases. Immediately after isolation, neutrophils $\left(1 \times 10^{6}\right.$ cells $)$ from patients and controls were incubated in sterile round-bottom polypropylene tubes with RPMI medium alone, or RPMI supplemented with $30 \mathrm{~nm}$ PMA for $25 \mathrm{~min}$ at $37^{\circ} \mathrm{C}, 5 \% \mathrm{CO}_{2}$. Samples were then incubated with $10 \mu \mathrm{M} \mathrm{H}_{2}$ DCFDA dissolved in DMSO for $30 \mathrm{~min}$ at $37^{\circ} \mathrm{C}$, after which DCF MFI was measured by flow cytometry (excitation wavelength, $488 \mathrm{~nm}$ ). After gating away cellular debris, the geometric mean fluorescence values of spontaneous and stimulated samples were recorded from CD66b ${ }^{+}$ cells.

Statistical analyses. Continuous data were summarised as arithmetic means with s.d.'s or medians with ranges according to data distribution. Baseline characteristics of patients, CD47, neutrophils and cytokines expression levels were compared using Student's $t$ tests or Mann-Whitney $U$-tests (according to data distribution determined by the Kolmogorov Smirnov test), and $\chi^{2}$-tests. The correlation among the percentage of phagocytosis and MFI of $\mathrm{CD} 47$ of $\mathrm{CD} 6 \mathrm{~b}^{+}$was computed by linear regression and analysed by Spearman test. Overall survival (OS) curves were estimated by the Kaplan-Meier method while comparisons among groups were analysed with log-rank or Breslow tests. Statistically significant and borderline variables ( $P$-values $\leqslant 0.1$ ) were included in the Cox multivariate analysis. Statistical significance was determined as $P \leqslant 0.05$ with a two-sided test. All data were analysed using the SPSS software package version 20 (SPSS, Inc., Chicago, IL, USA).

Study approval. This study was approved by the Institutional Review Board and Ethics Committee (INCAN (013/020/ICI) $(\mathrm{CV} 773 / 13))$ from the National Institute of Cancer.

All subjects signed a written informed consent form before inclusion in the study.

\section{RESULTS}

Clinical characteristics of NSCLC patients and healthy subjects. Supplementary Table 1 shows the baseline clinical characteristics of treatment-naive NSCLC patients $(N=50)$ and healthy subjects $(N=25)$ included in this study. Both groups had an even distribution, with no significant differences found with regards to age or gender. Significant differences were found with regards to smoking history $(46 \%$ vs $12 \% ; P=0.004)$ and wood-smoke exposure ( $40 \%$ vs $4 \%$; $P=0.001)$, which were more commonly reported among NSCLC patients. Approximately $84 \%$ of patients had adenocarcinoma and $90 \%$ presented stage IV disease. Central nervous system metastases at the time of diagnosis were found in $14 \%$ of the patients and pleural effusion in $50 \%$. Finally, $86 \%$ of patients presented a functional performance status (ECOG) of 1 . The haematologic characteristics of treatment-naive patients are 
summarised in Supplementary Table 1. Approximately 64\% of the patients exhibited a white blood cell count within normal parameters $\left(1.5-7.7 \times 10^{9} 1^{-1}\right)$. Leukocytosis (leukocytes $>10 \times 10^{9} 1^{-1}$ ) was present in $28 \%$ of the patients ( 14 out of50). Neutrophilic leukocytosis (leukocytes $>10 \times 10^{9} 1^{-1}$ and an absolute neutrophil count (ANC) $>7.7 \times 10^{9} 1^{-1}$ ) was present in $20 \%$ of patients. Only $2 \%$ of the patients ( 1 out of 50 ) exhibited isolated neutrophilia (ANC $>7.7 \times 10^{9} 1^{-1}$ with a leukocyte count within normal parameters). Neutropenia (ANC $<1.5 \times 10^{9} 1^{-1}$ ) was present only in $4 \%$ of the patients ( 2 out of 50 ).

Neutrophil frequency. As shown in Figure 1A, the granulocytic and lymphocytic populations (leukocytes) were selected from the FSC-A vs SSC-C dot plot and neutrophils were identified based on CD66b expression. The percentage of neutrophils $\left(\mathrm{CD} 6 \mathrm{~b}^{+}\right.$cells) was significantly elevated in patients as compared to healthy donors (56.5 \pm 17.5 vs $37.5 \pm 7.6 ; \quad P<0.001$; Figure $1 \mathrm{~B}$ and Supplementary Table 2). Similarly, the expression level of CD66b (measured as MFI) was also significantly higher in neutrophils obtained from NSCLC patients as compared to those from controls $(6938 \pm 2333$ vs $2994 \pm 2449 ; \quad P<0.0178$; Figure $1 \mathrm{C}$ and Supplementary Table 2).

Expression of CD47 in peripheral blood cells and neutrophils. Whole-blood expression of CD47 in patients and controls was evaluated by flow cytometry following the gating strategy shown in (Figure 1D). The percentage of $\mathrm{CD} 47^{+}$cells in whole blood was similar in patients and controls (median 82.1\% (67.8-99.3) vs $89.2 \%(66.5-91.5) ; \quad P=0.142$; Figure $1 \mathrm{E}$ and Supplementary Table 2). However, the abundance of CD47 in a per cell basis, quantified as MFI, was significantly higher in NSCLC patients (22 464 (15204-28 814) vs 16455 (14 542-17 061); $P=0.0408$; Figure $1 \mathrm{~F}$ and Supplementary Table 2). Similarly, when the expression of CD47 was evaluated in the neutrophil population $\left(\mathrm{CD} 66 \mathrm{~b}^{+}\right)$, the levels of CD47 were markedly higher in patients than in controls $(600.7 \pm 198$ vs $255.9 \pm 106.6$; $P<0.001$; Figure $1 G$ and Supplementary Table 2).

Neutrophil oxidative state. No significant differences were found between patients and healthy subjects with regards to spontaneous ROS production. In contrast, the levels of ROS produced after PMA stimulation were significantly $(P=0.0286)$ higher in neutrophils from patients (34 $405(28664-47540))$ than in neutrophils from healthy subjects (19061 (14307-27 499); Figure 2).

Caspase activation and spontaneous apoptosis in neutrophils. Spontaneous apoptosis, assessed as Annexin V binding and membrane permeability to 7-AAD, was significantly lower in neutrophils from patients with NSCLC than in those from healthy controls after $24 \mathrm{~h}$ of ex vivo culture (10.59 vs 18.28; $P=0.0317$; Figure $3 \mathrm{C}$ and $\mathrm{D}$ ). In line with this, samples from healthy subjects exhibited a higher percentage of fluorescent cells, indicative of caspase-3/7 activation, than samples from NSCLC patients (506.8 vs 145.4; $P=0.0079$; Figure $3 \mathrm{~A}$ and $\mathrm{B}$ ).

In vitro macrophage phagocytosis of control and patient-derived neutrophils. To assess the rate at which macrophages engulf either patient- or control-derived neutrophils, the fluorescence of $\mathrm{CMFDA}^{+} \mathrm{CD}^{-} \mathrm{b}^{-}$cells was quantified by flow cytometry according to the gating strategy shown in Figure 4A. This population represents macrophages that incorporated the dye through the engulfment of neutrophils. The percentage of $\mathrm{CMFDA}^{+} \mathrm{CD} 6 \mathrm{~b}^{-}$macrophages was lower in NSCLC samples as compared to controls (65.02 (52.0-78.8) vs 79.10 (70.0-88.0); $P=0.0445$; Figure 4B). To determine whether increased neutrophil expression of CD47 was associated with the observed reduction in the phagocytic index, we sought a correlation between expression of CD47 and the phagocytic index (Figure 4D). To this end, the expression of CD47 was evaluated in parallel blood samples (i.e., from the same patients/controls) as the ones used to determine the phagocytic index. In accordance with the results from the complete cohort previously shown (Figure $1 G$ ), in this subset of patients the expression of CD47 in CD66 $\mathrm{b}^{+}$cells was higher than in controls (22 464 (15 204-28 814) vs 16455 (14542-17 061); $P=0.0408$; Figure $4 \mathrm{C}$ ). The results from the correlation analysis are shown in Figure 4D where a significant negative association between CD47 expression and macrophage phagocytosis can be clearly observed $\left(r^{2}=-0.7179 ; P=0.0039\right)$.

Factors associated with OS. The median follow-up of patients was 16.9 months, with a range of 9.2-24.6 months. The mean OS was 17.5 months (95\% CI 14.015-21.067; Supplementary Table 6). Patients with NSCLC were divided into two groups according to the median expression of CD47 in whole blood and OS in each group was compared. The group of NSCLC patients whose CD47 expression in whole blood was $\leqslant 1635.5$ did not reach the median survival at the time of the last follow-up. In contrast, the group of patients whose CD47 MFI exceeded 1635.5 had a significantly lower OS (13.6 months (4.3-22.8); $P=0.007$; Figure 5A). In a multivariate analysis, high expression of CD47 in whole blood was an independent predictive factor of poor OS (RR 3.46 (95\% CI 1.29.7); $P=0.018$; Figure 5C).

When groups were dichotomised according to the median expression of CD47 in neutrophils $\left(\mathrm{CD} 6 \mathrm{~b}^{+}\right.$cells) a similar trend was observed, albeit without statistical significance. Whereas the majority of patients in the low CD47 group were alive at the last follow-up (OS: NR), those in the high CD47 group exhibited a lower OS (13.6 months (1.4-25.9); $P=0.140$; Figure 5B). The expression of CD47 in whole blood was significantly higher in patients with stage IV disease than in patients with stage IIIB (1783 MFI vs 975 MFI; $P=0.020$; Supplementary Table 3). There was a tendency, which did not reach statistical significance, for high CD47 expression to correlate with the presence of oligometastases $(P=0.064$; Supplementary Table 3$)$. The expression of CD47 in whole blood was significantly higher among patients with low albumin levels $\left(\leqslant 3.4 \mathrm{mg} \mathrm{dl}^{-1}\right)$ than in those with higher albumin levels (2501.5 vs 1316; $P=0.021)$. Low albumin levels $(<3.4)$ were associated with lower median OS $(P<0.001$; Supplementary Table 7). In agreement with this, in a multivariate analysis, the level of serum albumin was an independent predictive factor of OS (0.49 (0.25-0.95); $P=0.037$; Figure 5C). Other factors such as clinical and demographic characteristics (gender, age $>60$, smoking history, tumour histology, oligometastases and CNS metastases at the time of diagnosis) did not impact median OS (Supplementary Table 6). There was a tendency for patients with ECOG 1 and clinical stage IIIB to have a better OS (Supplementary Table 6).

Association between plasma cytokines and CD66b/CD47 percentage and expression. The plasma levels of various proinflammatory cytokines were evaluated. Compared to healthy donors, patients had significantly higher levels of IL-8, IL-12p70, IL-29, IL-31 and IL-32 in plasma (Supplementary Table 4). Furthermore, there was a significant correlation between the expression of CD47 in whole blood and the levels of both IL-8 $(r=0.45 ; P=0.0051)$ and IL-4 $(r=0.44 ; P=0.0126)$. These correlation coefficients indicate that the expression of CD47 increases together with that of IL- 8 and IL-4 (Figure 6A and B and Supplementary Table 5). Similarly, there was a strong correlation between the percentage of CD47-positive cells in whole blood and the plasma levels of both IL-4 $(r=0.39 ; P=0.0297)$ and IL-12 $(r=0.54 ; P=0.0016$; Figure $6 \mathrm{C}$ and $\mathrm{D}$ and Supplementary Table 5). There was also a significant association between the percentage of $\mathrm{CD} 6 \mathrm{~b}^{+}$cells and the plasma levels of IL-4 $(r=0.35$; $P=0.0479)$, IL-8 $\quad(r=0.51 ; P=0.0014) \quad$ and IL-31 $\quad(r=0.35$; $P=0.0494$; Figure $6 \mathrm{E}-\mathrm{G}$ and Supplementary Table 5). Finally, the expression of CD47 in neutrophils positively correlated with 
A
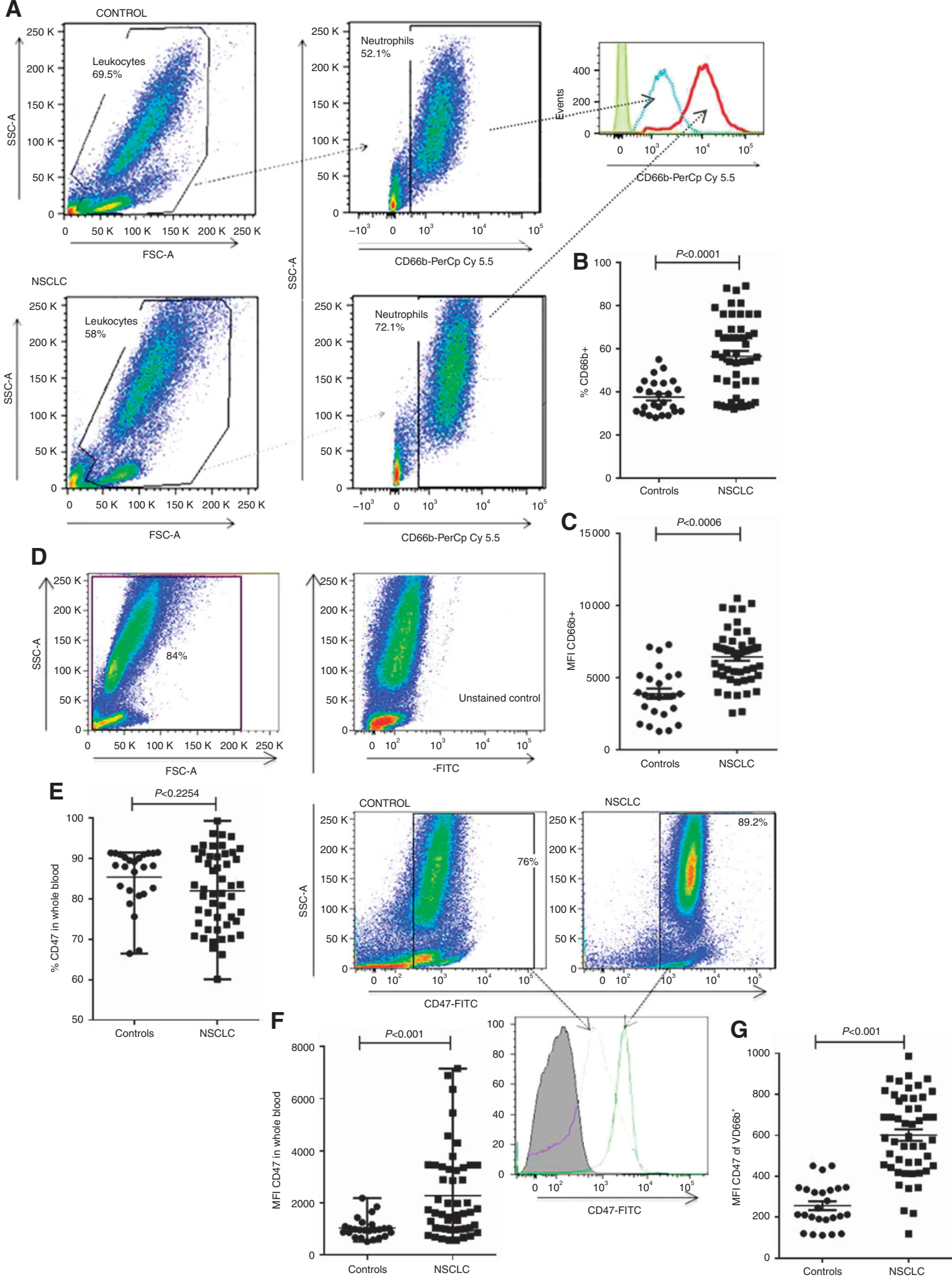

Figure 1. Neutrophil abundance and expression of CD47 in NSCLC patients and controls. Gating strategy for the flow cytometry analysis performed in whole-blood samples from patients and healthy donors. From the FSC-A vs SSC-C dot plot, the granulocytic and lymphocytic populations (leukocytes) were analysed. (A) Neutrophils were identified based on CD66b expression and physical characteristics (SSC). Positive cells for CD66b correspond to neutrophils. The histogram represents the MFI of the CD66b marker. The green line is the fluorescence minus one control (FMO), the blue line corresponds to the control subject and red line to a patient. (B) Scatter plot showing the frequency of neutrophils $\left(\mathrm{CD} 66 \mathrm{~b}^{+}\right.$cells) and CD66b MFI (C) in peripheral blood samples from NSCLC patients and controls. (D) CD47 expression was quantified in leukocytes identified based on FSC and SSC (left dot plot). The gate used to define CD47 ${ }^{+}$cells was set using the FMO control (FITC ${ }^{-}$). Shown are representative dot plots from a control and a patient, and a histogram to illustrate the differences in the expression of CD47 (grey shade indicates FMO, purple line corresponds to a control subject and green line to a patient). (E) Scatter plot showing the frequency of CD47 ${ }^{+}$cells in whole blood of controls and NSCLC patients. (F) Scatter plot showing the MFI of CD47 in peripheral blood cells. (G) MFI of CD47 in CD66b ${ }^{+}$cells (neutrophils) from NSCLC patients and controls. Each symbol represents one individual (controls, $N=25$; patients, $N=50$ ). Lines indicate mean \pm s.e.m. Means were compared using unpaired $t$-tests $(\mathbf{B}, \mathbf{C}, \mathbf{G})$ or unpaired Mann-Whitney tests $(\mathbf{E}, \mathbf{F})$. 
A CONTROL
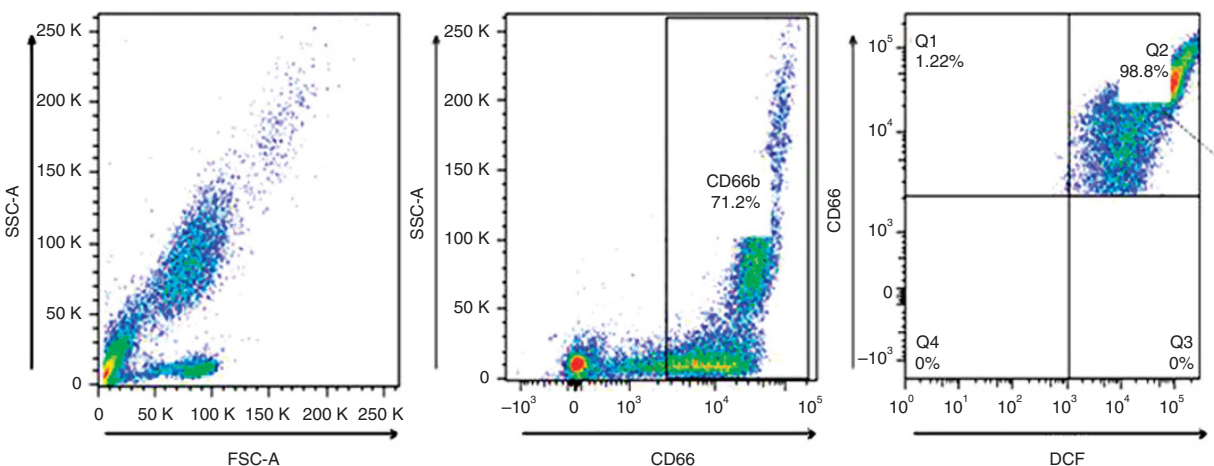

NSCLC
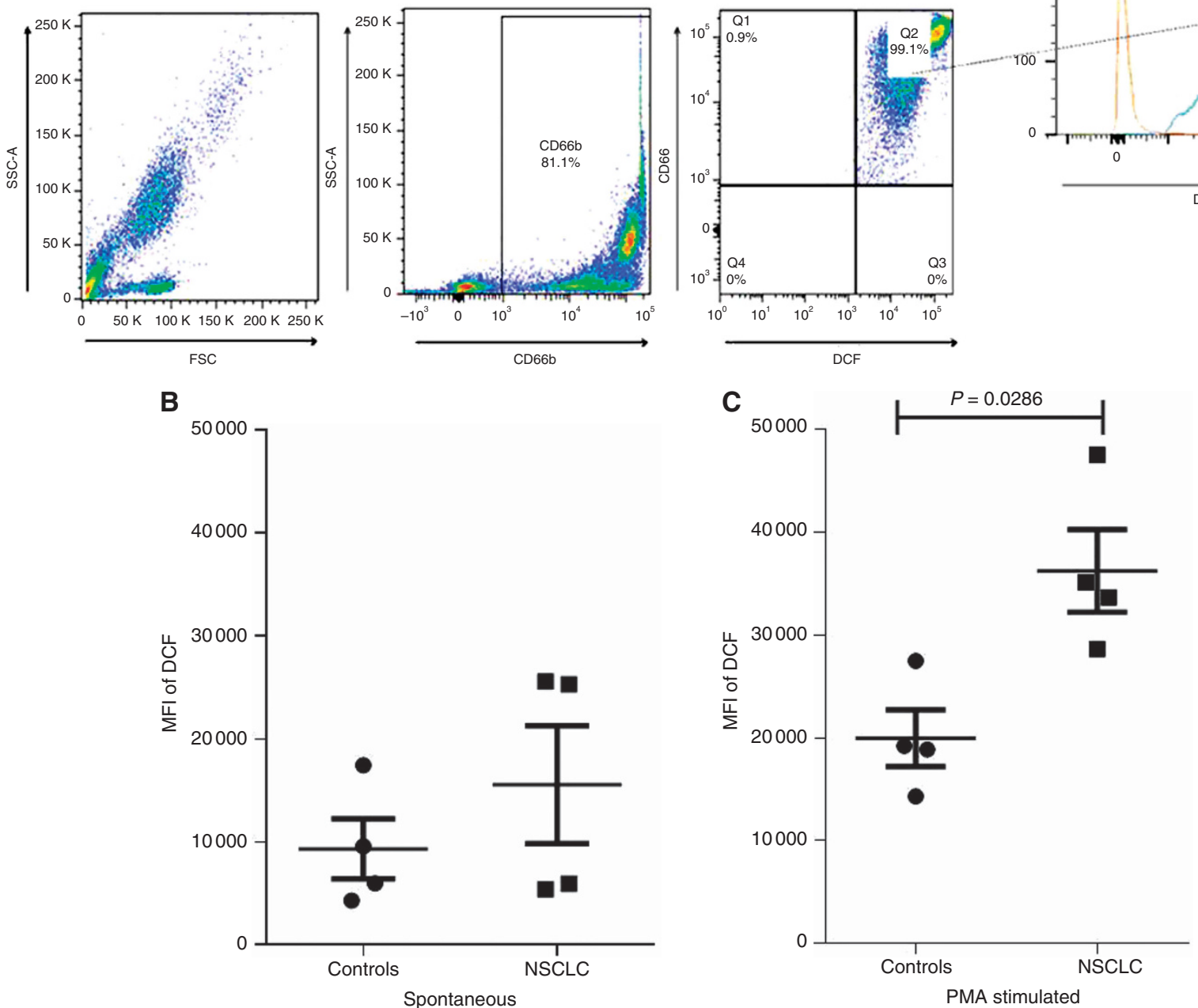

Figure 2. Spontaneous and PMA-induced ROS production in circulating neutrophils. (A) 2',7'-dichlorodihydrofluorescein diacetate (DCF) fluorescence was used as an indicator of ROS production in neutrophils identified based on CD66b expression and physical characteristics. Shown are representative dot plots from a patient, and a control and a histogram comparing ROS production in neutrophils from a patient (red line) and a control (blue line). The yellow line indicates the FMO control. (B) Scatter plot showing spontaneous ROS (DCF MFI) production by neutrophils from patients and controls. (C) Scatter plot showing PMA-stimulated ROS production. Each symbol represents one individual (controls, $n=4$; patients, $n=4)$. Lines indicate mean \pm s.e.m. Unpaired t-test analyses were performed.

the plasma levels of IL-4 $(r=0.39 ; P=0.0297)$ and IL-31 $(r=0.39$; $P=0.0297$; Figure $6 \mathrm{H}$ and $\mathrm{I}$ and Supplementary Table 5).

\section{DISCUSSION}

Patients with NSCLC often exhibit neutrophilic leukocytosis (neutrophilia) at the time of diagnosis or during the course of the disease. Several studies have confirmed that neutrophil content, both local and systemic, inversely correlates with positive outcomes. In particular, the neutrophil-lymphocyte ratio has emerged as an independent and reliable prognostic factor for patients with lung cancer, in both early (Tomita et al, 2012; Yao et al, 2013; Tanoglu et al, 2014; Zhang et al, 2015) and advanced stages (Arrieta et al, 2010; Sanchez-Lara et al, 2012; Gu et al, 2015; Peng et al, 2015; Yin et al, 2015). However, much uncertainty still exists about the underlying mechanisms that lead to neutrophilia in the context of cancer. 
A
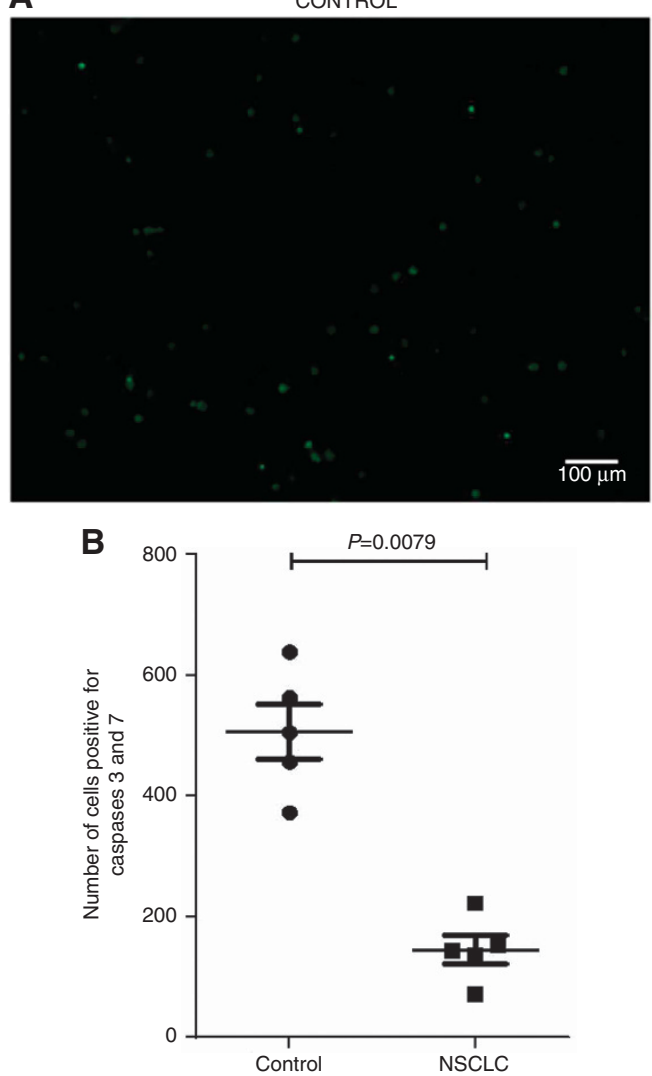

NSCLC
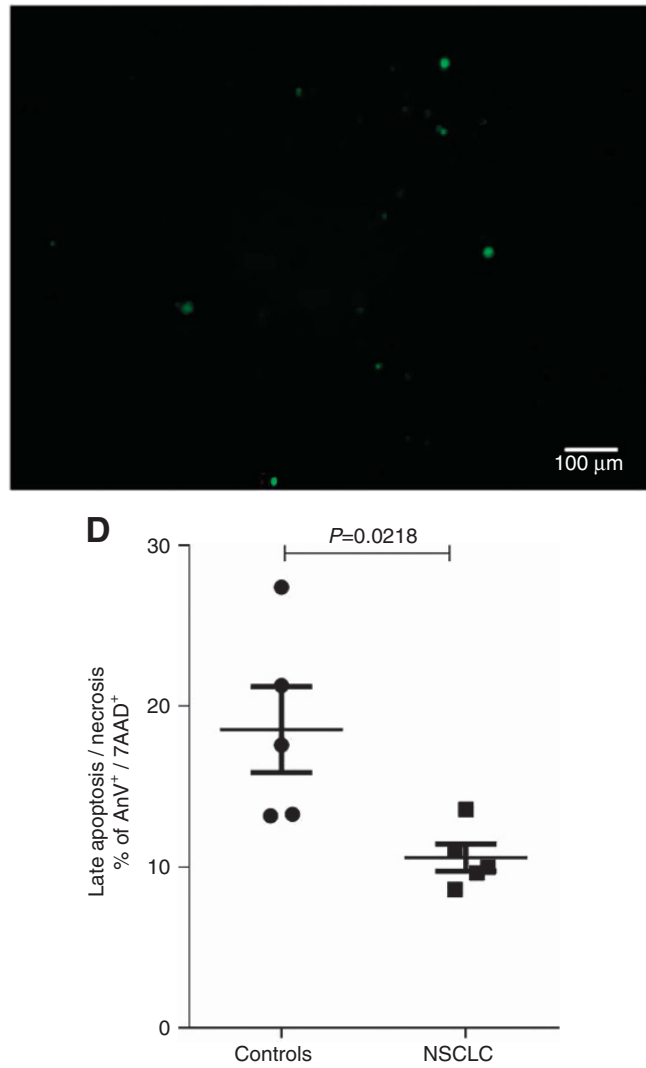

C CONTROL
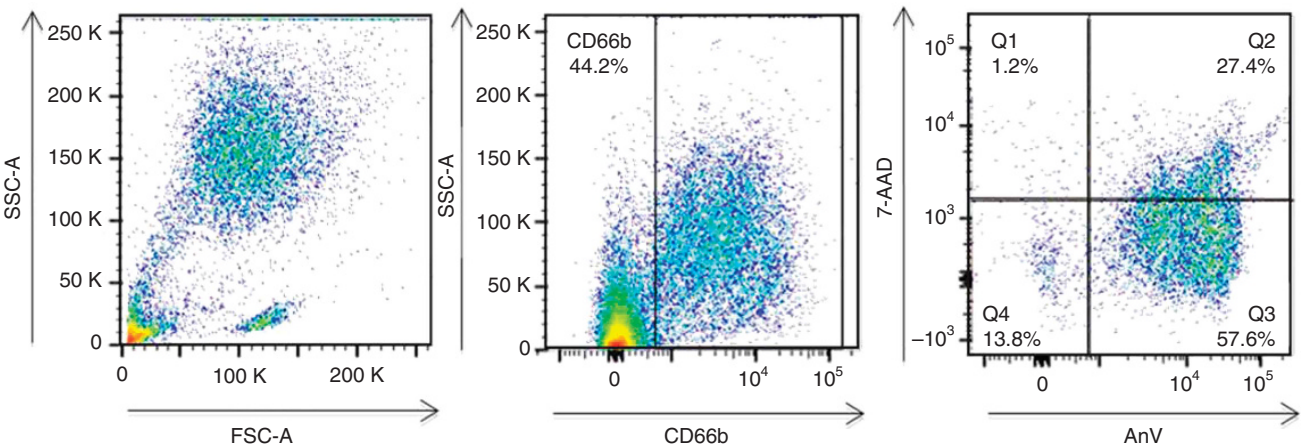

NSCLC
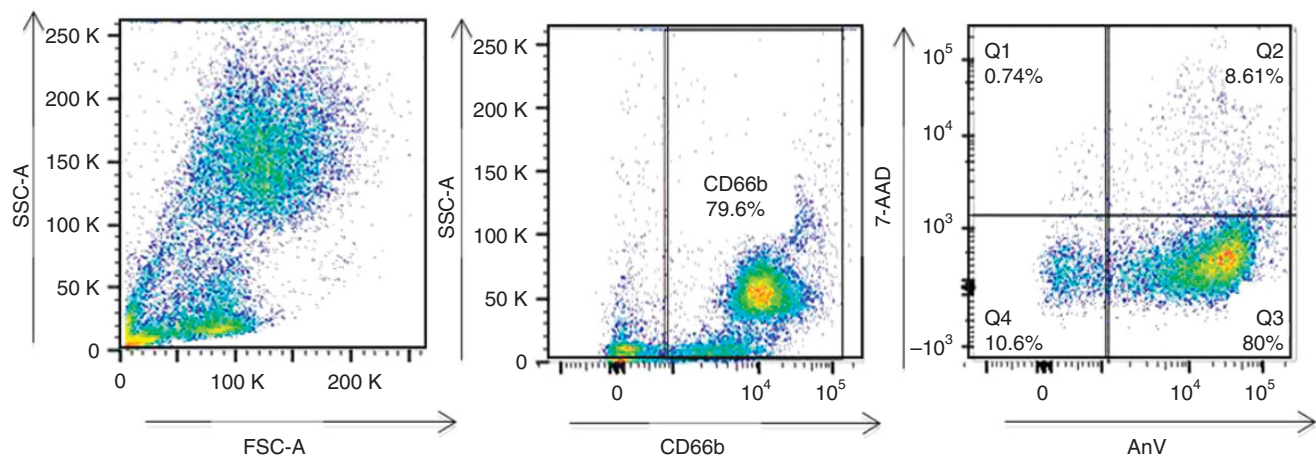

Figure 3. Spontaneous apoptosis in neutrophils from patients and controls. The PMNs from patients with NSCLC and healthy donors were isolated from peripheral blood and incubated during $24 \mathrm{~h}$. Spontaneous apoptosis was quantified by counting cells with activated caspases 3 and 7, and by quantifying Annexin V- and 7-AAD-positive cells. (A) Representative micrographs showing caspase 3 and 7 activation (green fluorescence). (B) Number of PMN cells positive for caspases 3 and $7(n=5)$. (C) Neutrophils were gated as detailed previously, and Annexin $V$-APC and 7-AAD fluorescence was measured. (D) Scatter plot showing the percentage of cells positive for Annexin V and 7-AAD (late apoptosis/ necrosis). Each symbol represents one individual (controls, $n=5$; patients, $n=5$ ). Lines indicate mean \pm s.e.m. Unpaired $t$-test analyses were performed. 

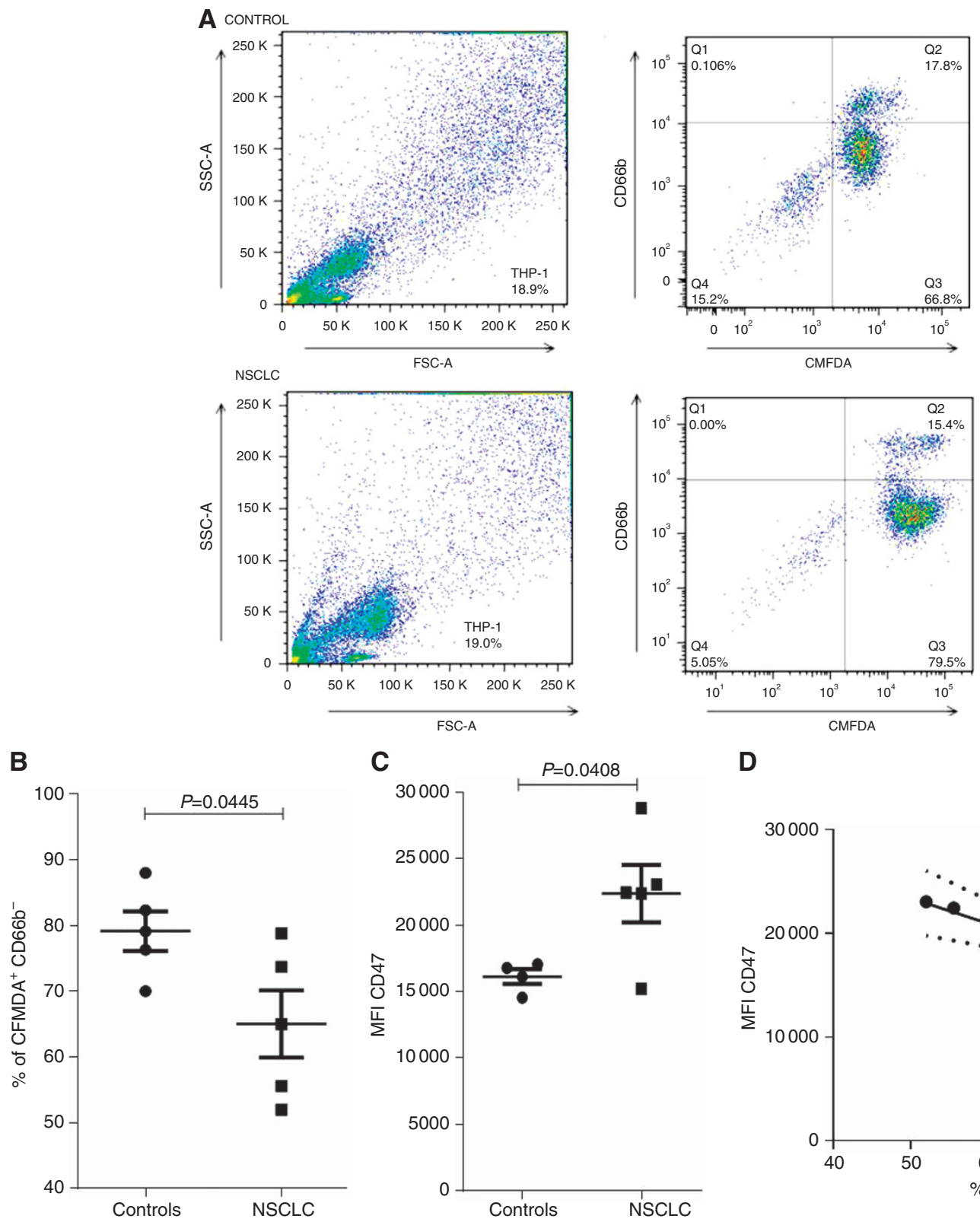

D

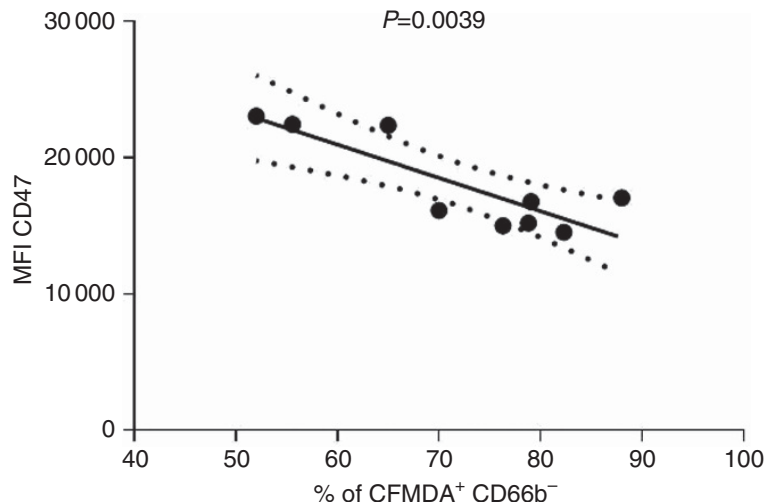

Figure 4. Phagocytosis of neutrophils from NSCLC patients and controls. (A) Neutrophils from patients and controls were labelled with CMFDA and incubated with macrophages. Neutrophil engulfment was quantified by counting the fraction of CD66b ${ }^{-}$cells positive for CMFDA. (B) Scatter plot showing the percentage of macrophages that engulfed neutrophils (CMFDA ${ }^{+} \mathrm{CD}_{6} 6 b^{-}$) from patients and controls. (C) CD47 expression in neutrophils from patients and controls. (D) Spearman correlation of CD47 expression in neutrophils vs \% of CFMDA ${ }^{+}$CD $66 b^{-}$cells $\left(r^{2}=-0.7179\right)$. Each symbol represents one individual (controls, $n=5$; patients, $\left.n=5\right)$. Lines indicate mean \pm s.e. $m$. Unpaired $t$-test analyses were used to compare means.

Neutrophil homeostasis is maintained by a fine balance between granulopoiesis, bone marrow retention and mobilisation, intravascular margination and clearance from the system (Tak et al, 2013; SilvestreRoig et al, 2016). Several parameters of the neutrophil life cycle were evaluated in the current study, with special emphasis on the activation state of neutrophils and the mechanisms by which neutrophils are removed in patients with NSCLC. Our results show that the number of neutrophils (percentage of CD66b-positive cells in whole blood) and the level of expression of CD66b (measured on a per cell basis) is increased in NSCLC patients as compared to controls. CD66b is a GPI-anchored glycoprotein of the carcinoembryonic antigen family that is located in the specific granules (Ducker and Skubitz, 1992). Increased expression of $\mathrm{CD} 66 \mathrm{~b}$ is caused by degranulation of specific granules and represents a surrogate marker of neutrophil activation (Faurschou and Borregaard, 2003).
Neutrophils utilise a wide array of mechanisms to exert their effector functions during infection and wound healing. In addition to releasing granules, activated neutrophils have been shown to produce high amounts of ROS. Therefore, to further assess the activation state of neutrophils, ROS production was evaluated using a broad spectrum fluorescent probe. Although no significant differences were noted in the relative oxidative activity of neutrophils between patients and controls, neutrophils isolated from patients exhibited a higher oxidative potential than those isolated from controls, as evidenced by the significantly higher production of ROS in patient-derived neutrophils stimulated with PMA. Various functions of mature neutrophils are activated by pro-inflammatory cytokines, which can lead to the secretion of superoxide anion $\left(\mathrm{O}_{2}^{-}\right)$and other ROS with activation of NADPH-oxidase through the activation of MAPK/ extracellular signal-regulated kinase (Suzuki et al, 1999, 2001). 

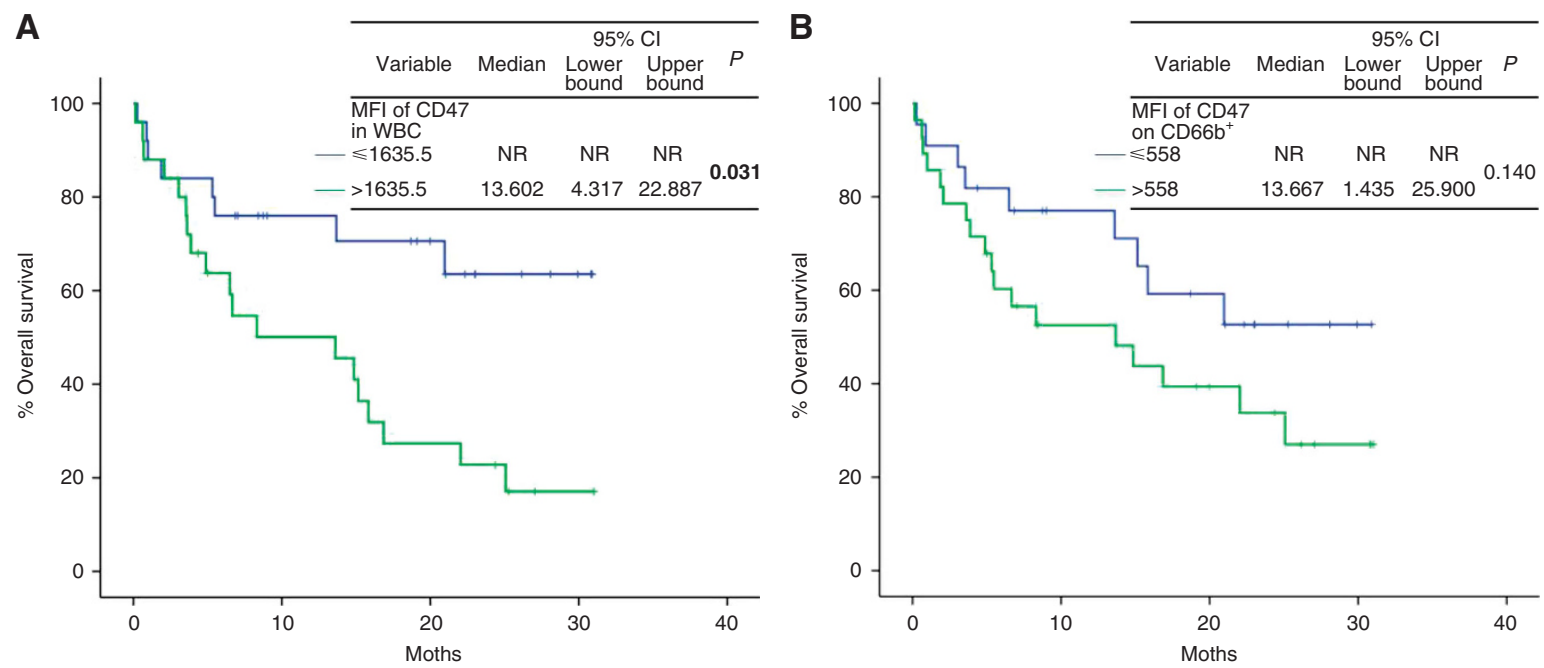

\begin{tabular}{|c|c|c|c|c|}
\hline \multicolumn{5}{|c|}{ Multivariate analysis of overall survival. } \\
\hline & \multirow{2}{*}{ HR } & \multicolumn{2}{|c|}{$95 \%$ confidence interval } & \multirow{2}{*}{$P$} \\
\hline & & Lower bound & Upper bound & \\
\hline Clinical stage & 1.102 & 0.118 & 10.282 & 0.932 \\
\hline ECOG & 1.356 & 0.361 & 5.097 & 0.653 \\
\hline 1635.5 MFI CD47 & 3.467 & 1.233 & 9.752 & 0.018 \\
\hline Neutrophils (thousands per $\mathrm{mm}^{3}$ ) & 1.094 & 0.952 & 1.258 & 0.206 \\
\hline Albumin $\left(\mathrm{mg} \mathrm{dl}^{-1}\right)$ & 0.490 & 0.251 & 0.957 & 0.037 \\
\hline
\end{tabular}

Figure 5. Kaplan-Meier overall survival (OS) curve according to CD47 expression. (A) Survival analysis of patients dichotomised according to CD47 expression in whole-blood cells. The cut-off point (1635.5) of CD47 corresponds to the median MFI value in whole-blood cell samples. (B) Survival analysis of patients dichotomised according to CD47 expression in CD66b ${ }^{+}$cells. The cut-off point (558) of CD47 was determined using ROC curves. (C) Multivariate analysis of factors involved in OS.

Interleukin-8, a member of the $\mathrm{ELR}^{+} \mathrm{CXC}$ chemokine family, induces neutrophils to leave the bloodstream and promotes neutrophil recruitment into the airways during lung cancer (Carpagnano et al, 2011). Furthermore, previous studies have shown that neutrophils can release IL-8 under various circumstances (Marchi et al, 2014). Indeed, it has been suggested that neutrophil-derived IL-8 can promote angiogenesis (Tecchio et al, 2013). In agreement, our results indicate that the plasma levels of IL-8 are higher in patients than in controls. Furthermore, there was a correlation between the levels of IL- 8 and the percentage of circulating neutrophils. It is thus likely that IL- 8 increases the number of neutrophils in the peripheral blood of NSCLC patients, perhaps through the inhibition of apoptosis and in an autocrine manner as it has been previously reported (Dumas et al, 2012).

Although IL-4 has been largely regarded as an anti-inflammatory cytokine (Woytschak et al, 2016), there is evidence indicating that it also has important pro-inflammatory functions. It has been previously shown that IL-4 promotes the recruitment of eosinophils, macrophages, fibroblasts, $\mathrm{B}$ cells and more recently neutrophils (Ratthe et al, 2009). Furthermore, a previous report by the same group demonstrated that IL-4 delays neutrophil apoptosis and increases neutrophil IL-8 production (Girard et al, 1997). Indeed, previous reports have shown that IL-4 protects B cells from spontaneous and induced apoptosis (Lemaire et al, 1999), and, in lung cancer, IL-4 functions as an autocrine growth factor that prevents the induction of apoptosis in neoplastic cells (Todaro et al, 2008). In addition, we found a significant correlation between the levels of IL-4 and the expression of CD47 in neutrophils, which may be another mechanism involved in the anti-apoptotic effect of IL-4 on neutrophils. Our results, which show a correlation between the frequency of circulating neutrophils and the levels of IL-4 and IL-8, indicate that a similar pro-inflammatory anti-apoptotic mechanism may underlie neutrophilia in patients with NSCLC.

In vivo studies have shown that under physiological conditions neutrophils undergo spontaneous apoptosis (Filep and El Kebir, 2009). Similarly, it has been shown that neutrophils in culture spontaneously produce ROS, which in turn induces apoptosis (Aoshiba et al, 1999; Scheel-Toellner et al, 2004). Given that NSCLC patients exhibited an increase in the number of neutrophils without signs of an increase in the number of immature neutrophils, we hypothesised that the rate at which neutrophils undergo cell death could be decreased in NSCLC patients. To explore this possibility, neutrophils isolated from both patients and controls were kept in vitro for $24 \mathrm{~h}$, after which the rate at which neutrophils undergo spontaneous cell death was evaluated. Unlike neutrophils obtained from controls, cultured neutrophils from NSCLC patients had lower levels of extracellular Annexin V and 7$\mathrm{AAD}$ as well as lower levels of activated caspase 3 and 7 , indicating a delay in apoptosis.

Although phagocytosis is generally viewed as the culminating step of programmed cell death, there is evidence suggesting that non-apoptotic neutrophils can be phagocytosed by macrophages at the same rate as apoptotic neutrophils (Lagasse and Weissman, 1994). Our results show that patient-derived neutrophils are phagocytosed at a lower rate than those obtained from healthy donors. Patient-derived neutrophils showed an increase in the expression of CD47, which negatively correlated with the rate at which they were phagocytosed.

CD47 is ubiquitously expressed in human cells where it acts as a 'marker of self. CD47 inhibits phagocytosis through its binding to SIRP- $\alpha$, a receptor found on the surface of phagocytic cells, including macrophages and dendritic cells (Zhao et al, 2011; Feng et al, 2015). Binding of CD47 to SIRP- $\alpha$ causes the phosphorylation 

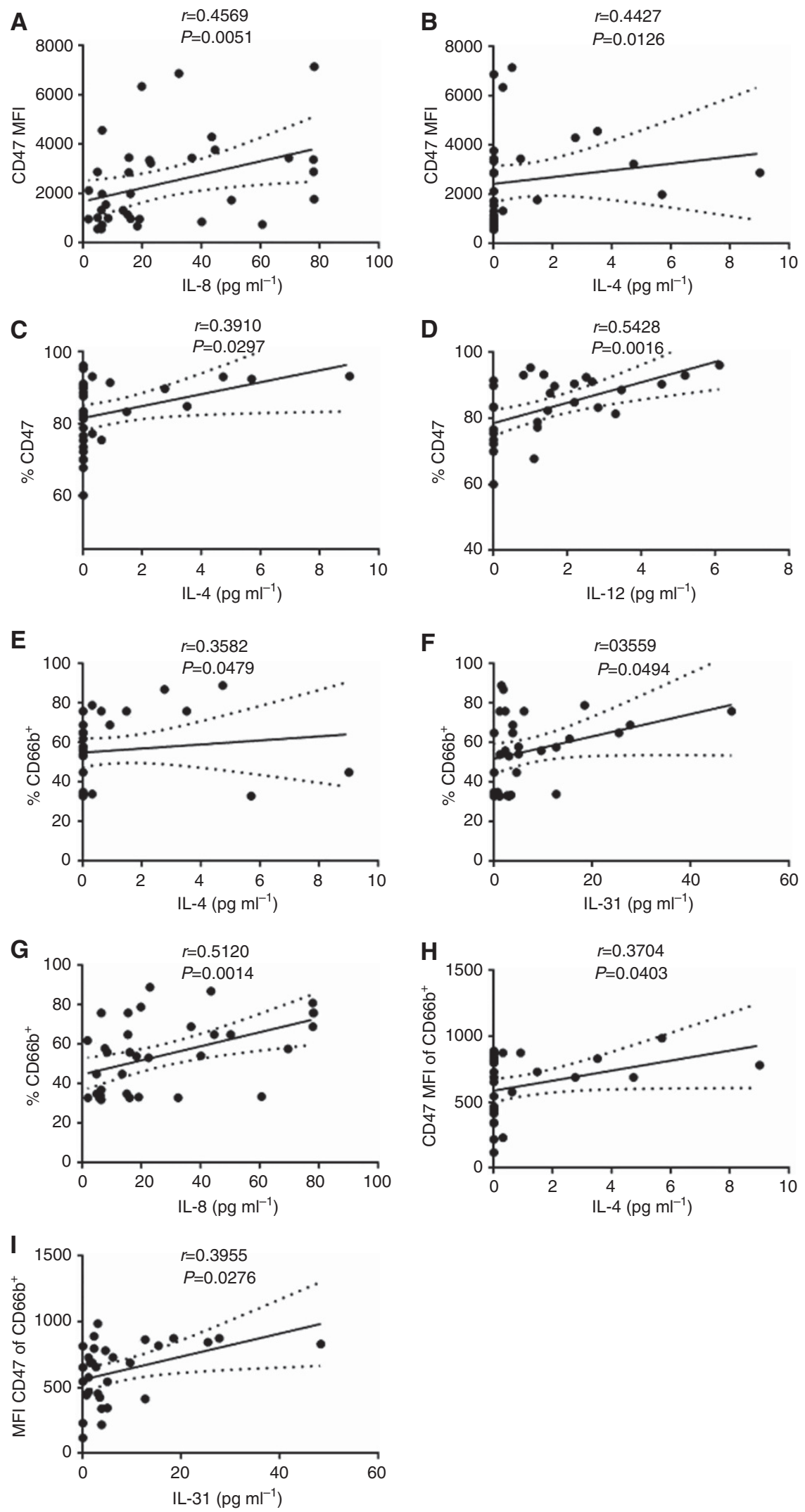

Figure 6. Linear regression and correlation between plasma cytokine levels and CD66b/CD47 percentage/expression. Correlation between CD47 expression (in whole blood) and plasma levels of IL-8 (A) and IL-4 (B). Correlation between the percentage of CD47 ${ }^{+}$cells (in whole blood) and plasma levels of IL-4 (C) and IL-12 (D). Correlation between the percentage of CD66b ${ }^{+}$(neutrophils) and the plasma levels of IL-4 (E), IL-31 (F) and IL-8 (G). Correlation between CD47 expression (in CD66b ${ }^{+}$cells) and plasma levels of IL-4 (H) and IL-31 (I). Statistical analyses were performed using the Spearman correlation test. Each symbol represents one patient $(n=31)$. 
of the immunoreceptor tyrosine-based inhibitory motif on SIRP- $\alpha$, the recruitment of Src homology region 2 domain-containing phosphatase (SHP)-1 and SHP-2 to the membrane, which inhibits myosin-IIA accumulation at the phagocytic synapse, ultimately resulting in the inhibition of phagocytosis (Fujioka et al, 1996).

Conversely, CD47-deficient circulating cells are rapidly cleared by splenic macrophages (Brown and Frazier, 2001). Thus, it is possible that in patients with NSCLC, CD47 overexpression may cause an increase in the number of circulating neutrophils by reducing their clearance from the system. It has been reported that cancer cells and circulating tumour cells may express CD47 as a mechanism to avoid immune system attack (Chao et al, 2012; Eruslanov et al, 2014; McCracken et al, 2015). Indeed, CD47 overexpression has been found in haematologic malignancies (Jaiswal et al, 2009; Majeti et al, 2009), gastric cancer (Yoshida et al, 2015) and NSCLC (Zhao et al, 2016), where its expression correlates with a bad prognosis.

Several studies have shown that high CD47 expression in tumours correlates with poor prognosis. However, to the best of our knowledge, this is the first study in NSCLC patients in which the level of expression of CD47, evaluated in whole-blood samples, negatively correlates with OS. Indeed, the survival analysis of groups according to the level of expression of CD47 in peripheral whole blood shows that patients with low expression of CD47 have a better OS than patients with high CD47 expression. Although the survival analysis of patients according to the expression of CD47 in neutrophils did not reach statistical significance, there was a trend suggesting that high CD47 expression in neutrophils leads to poorer survival outcomes. It is possible that the relatively small size of this cohort precluded the detection of any true differences that might exist. Alternatively, it is possible that the stark differences in survival observed from the whole-blood analysis are caused by the summed effect of other immune cell subsets in which CD47 expression is also increased. Although further mechanistic studies will likely determine the specific contribution of each immune cell subset, the translational relevance of the current study is supported by a previous report showing that CD47 overexpression in peripheral blood samples predicts recurrence in breast cancer patients (Nagahara et al, 2010). Thus, evaluating the expression of CD47 in whole blood could be used as a non-invasive method to identify patients with worse prognosis.

Recent studies have advanced CD47 as a novel molecular target for the use of therapeutic antibodies. Promising results have been obtained using anti-CD47 antibodies for the treatment of nonHodgkin lymphoma, breast, bladder, lung and ovarian carcinomas (Chao et al, 2010; Weiner et al, 2010; Pardoll, 2012). Our results suggest that an additional advantage of CD47-blocking therapies could be the control neutrophil accumulation. However, future research is warranted in order to determine the clinical implications of CD47-blocking strategies. Whereas it is likely that CD47 antibodies could have an overall positive effect on tumour control (Ilie et al, 2012), it remains unclear whether other antitumour immune cell subsets could be negatively affected.

\section{ACKNOWLEDGEMENTS}

This work was supported by the National Council of Science and Technology of Mexico (CONACYT; 161599 to LB and 87453 to OA.

\section{CONFLICT OF INTEREST}

José Rafael Borbolla-Escoboza is a full time AstraZeneca employee (Oncology Medical Affairs); Lourdes Barrera is a full time
AstraZeneca employee (Oncology GPPS). However, the authors declare no conflict of interests since no AstraZeneca or competitor molecules were tested. The remaining authors declare no conflict of interests.

\section{REFERENCES}

Anand U, Anand CV (2012) Myeloperoxidase: a new twist to an old tale. Indian J Clin Biochem 27: 107-109.

Aoshiba K, Nakajima Y, Yasui S, Tamaoki J, Nagai A (1999) Red blood cells inhibit apoptosis of human neutrophils. Blood 93: 4006-4010.

Arrieta O, Guzman-De Alba E, Alba-Lopez LF, Acosta-Espinoza A, AlatorreAlexander J, Alexander-Meza JF, Allende-Perez SR, Alvarado-Aguilar S, Araujo-Navarrete ME, Argote-Greene LM, Aquino-Mendoza CA, Astorga-Ramos AM, Austudillo-De LA Vega H, Aviles-Salas A, Barajas-Figueroa LJ, Barroso-Quiroga N, Blake-Cerda M, Cabrera-Galeana PA, Calderillo-Ruiz G, Campos-Parra AD, Cano-Valdez AM, Capdeville-Garcia D, Castillo-Ortega G, Casillas-Suarez C, Castillo-Gonzalez P, Corona-Cruz JF, Correa-Acevedo ME, Cortez-Ramirez SS, De La Cruz-Vargas JA,

De LA Garza-Salazar JG, De La Mata-Moya MD, Dominguez-Flores ME, Dominguez-Malagon HR, Dominguez-Parra LM, Dominguez-Peregrina A,

Duran-Alcocer J, Enriquez-Aceves MI, Elizondo-Rios A, Escobedo-Sanchez MD, de Villafranca PE, Flores-Cantisani A, Flores-Gutierrez JP, Franco-Marina F, Franco-Gonzalez EE, Franco-Topete RA, Fuentes-De La Pena H, Galicia-Amor S, Gallardo-Rincon D, Gamboa-Dominguez A, Garcia-Andreu J, Garcia-Cuellar CM, Garcia-Sancho-Figueroa MC, Garcia-Torrentera R, Gerson-Cwilich R, Gomez-Gonzalez A, Green-Schneeweiss L, Guillen-Nunez Mdel R, Gutierrez-Velazquez H, Ibarra-Perez C, Jimenez-Fuentes E, Juarez-Sanchez P, Juarez-Ramiro A, Kelly-Garcia J, Kuri-Exsome R, Lazaro-Leon JM, Leon-Rodriguez E, Llanos-Osuna S, Llanos-Osuna S, Loyola-Garcia U, Lopez-Gonzalez JS, Lopez Y, De Antunano FJ, Loustaunau-Andrade MA, Macedo-Perez EO, Machado-Villarroel L, Magallanes-Maciel M, Martinez-Barrera L, Martinez-Cedillo J, Martinez-Martinez G, Medina-Esparza A, Meneses-Garcia A, Mohar-Betancourt A, Morales Blanhir J, Morales-Gomez J, Motola-Kuba D, Najera-Cruz MP, Nunez-Valencia Cdel C, Ocampo-Ocampo MA, Ochoa-Vazquez MD, Olivares-Torres CA, Palomar-Lever A, Patino-Zarco M, Perez-Padilla R, Pena-Alonso YR, Perez-Romo AR, Aquilino Perez M, Pinaya-Ruiz PM,

Pointevin-Chacon MA, Poot-Braga JJ, Posadas-Valay R, Ramirez-Marquez M, Reyes-Martínez I, Robledo-Pascual J, Rodríguez-Cid J, Rojas-Marín CE, Romero-Bielma E, Rubio-Gutiérrez JE, Sáenz-Frías JA, Salazar-Lezama MA, Sánchez-Lara K, Sansores Martínez R, Santillán-Doherty P, Alejandro-Silva J, Téllez-Becerra JL, Toledo-Buenrostro V, Torre-Bouscoulet L, Torecillas-Torres L, Torres M, Tovar-Guzmán V, Turcott-Chaparro JG, Vázquez-Cortés JJ, Vázquez-Manríquez ME, Vilches-Cisneros $\mathrm{N}$, Villegas-Elizondo JF, Zamboni MM, Zamora-Moreno J, Zinser-Sierra JW (2013) National consensus of diagnosis and treatment of non-small cell lung cancer. Rev Invest Clin 65(Suppl 1): S5-S84.

Arrieta O, Michel Ortega RM, Villanueva-Rodriguez G, Serna-Thome MG, Flores-Estrada D, Diaz-Romero C, Rodriguez CM, Martinez L, Sanchez-Lara K (2010) Association of nutritional status and serum albumin levels with development of toxicity in patients with advanced non-small cell lung cancer treated with paclitaxel-cisplatin chemotherapy: a prospective study. BMC Cancer 10: 50 .

Azcutia V, Stefanidakis M, Tsuboi N, Mayadas T, Croce KJ, Fukuda D, Aikawa M, Newton G, Luscinskas FW (2012) Endothelial CD47 promotes vascular endothelial-cadherin tyrosine phosphorylation and participates in $\mathrm{T}$ cell recruitment at sites of inflammation in vivo. J Immunol 189: 2553-2562.

Brown EJ, Frazier WA (2001) Integrin-associated protein (CD47) and its ligands. Trends Cell Biol 11: 130-135.

Carpagnano GE, Palladino GP, Lacedonia D, Koutelou A, Orlando S, Foschino-Barbaro MP (2011) Neutrophilic airways inflammation in lung cancer: the role of exhaled LTB-4 and IL-8. BMC Cancer 11: 226.

Carus A, Gurney H, Gebski V, Harnett P, Hui R, Kefford R, Wilcken N, Ladekarl M, Von Der Maase H, Donskov F (2013) Impact of baseline and nadir neutrophil index in non-small cell lung cancer and ovarian cancer patients: assessment of chemotherapy for resolution of unfavourable neutrophilia. J Transl Med 11: 189. 
Chao MP, Alizadeh AA, Tang C, Myklebust JH, Varghese B, Gill S, Jan M, Cha AC, Chan CK, Tan BT, Park CY, Zhao F, Kohrt HE, Malumbres R, Briones J, Gascoyne RD, Lossos IS, Levy R, Weissman IL, Majeti R (2010) Anti-CD47 antibody synergizes with rituximab to promote phagocytosis and eradicate non-Hodgkin lymphoma. Cell 142: 699-713.

Chao MP, Majeti R, Weissman IL (2011) Programmed cell removal: a new obstacle in the road to developing cancer. Nat Rev Cancer 12: 58-67.

Chao MP, Weissman IL, Majeti R (2012) The CD47-SIRPalpha pathway in cancer immune evasion and potential therapeutic implications. Curr Opin Immunol 24: 225-232.

Ducker TP, Skubitz KM (1992) Subcellular localization of CD66, CD67, and NCA in human neutrophils. J Leukoc Biol 52: 11-16.

Dumas E, Martel C, Neagoe PE, Bonnefoy A, Sirois MG (2012) Angiopoietin1 but not angiopoietin-2 promotes neutrophil viability: role of interleukin8 and platelet-activating factor. Biochim Biophys Acta 1823: 358-367.

Eruslanov EB, Bhojnagarwala PS, Quatromoni JG, Stephen TL, Ranganathan A, Deshpande C, Akimova T, Vachani A, Litzky L, Hancock WW, Conejo-Garcia JR, Feldman M, Albelda SM, Singhal S (2014) Tumor-associated neutrophils stimulate $\mathrm{T}$ cell responses in early-stage human lung cancer. J Clin Invest 124: 5466-5480.

Faurschou M, Borregaard N (2003) Neutrophil granules and secretory vesicles in inflammation. Microbes Infect 5: 1317-1327.

Feng M, Chen JY, Weissman-Tsukamoto R, Volkmer JP, Ho PY, Mckenna KM, Cheshier S, Zhang M, Guo N, Gip P, Mitra SS, Weissman IL (2015) Macrophages eat cancer cells using their own calreticulin as a guide: roles of TLR and Btk. Proc Natl Acad Sci USA 112 2145-2150.

Filep JG, El Kebir D (2009) Neutrophil apoptosis: a target for enhancing the resolution of inflammation. J Cell Biochem 108: 1039-1046.

Fujioka Y, Matozaki T, Noguchi T, Iwamatsu A, Yamao T, Takahashi N, Tsuda M, Takada T, Kasuga M (1996) A novel membrane glycoprotein, SHPS-1, that binds the SH2-domain-containing protein tyrosine phosphatase SHP-2 in response to mitogens and cell adhesion. Mol Cell Biol 16: 6887-6899.

Gernez Y, Tirouvanziam R, Chanez P (2010) Neutrophils in chronic inflammatory airway diseases: can we target them and how? Eur Respir J 35: 467-469.

Girard D, Paquin R, Beaulieu AD (1997) Responsiveness of human neutrophils to interleukin-4: induction of cytoskeletal rearrangements, de novo protein synthesis and delay of apoptosis. Biochem J 325(Pt 1): 147-153.

Gitik M, Kleinhaus R, Hadas S, Reichert F, Rotshenker S (2014) Phagocytic receptors activate and immune inhibitory receptor SIRPalpha inhibits phagocytosis through paxillin and cofilin. Front Cell Neurosci 8: 104.

Global Burden of Disease CancerFitzmaurice C, Allen C, Barber C, Barregard RM, Bhutta L, Brenner ZA, Dicker H, Chimed-Orchir DJ, Dandona O, Dandona R, Fleming L, Forouzanfar T, Hancock MH, Hay J, Hunter-Merrill RJ, Huynh R, Hosgood C, Johnson HD, Jonas CO, Khubchandani JB, Kumar J, Kutz GA, Lan M, Larson Q, Liang HJ, Lim X, Lopez SS, Macintyre AD, Marczak MF, Marquez L, Mokdad N, Pinho AH, Pourmalek C, Salomon F, Sanabria Jr JA, Sandar L, Sartorius B, Schwartz SM, Shackelford KA, Shibuya K, Stanaway J, Steiner C, Sun J, Takahashi K, Vollset SE, Vos T, Wagner JA, Wang H, Westerman R, Zeeb H, Zoeckler L, Abd-Allah F, Ahmed MB, Alabed S, Alam NK, Aldhahri SF, Alem G, Alemayohu MA, Ali R, Al-Raddadi R, Amare A, Amoako Y, Artaman A, Asayesh H, Atnafu N, Awasthi A, Saleem HB, Barac A, Bedi N, Bensenor I, Berhane A, Bernabe E, Betsu B, Binagwaho A, Boneya D, Campos-Nonato I, Castaneda-Orjuela C, Catala-Lopez F, Chiang P, Chibueze C, Chitheer A, Choi JY, Cowie B, Damtew S, Das Neves J, Dey S, Dharmaratne S, Dhillon P, Ding E, Driscoll T, Ekwueme D, Endries AY, Farvid M, Farzadfar F, Fernandes J, Fischer F, G/Hiwot TT, Gebru A, Gopalani S, Hailu A, Horino M, Horita N, Husseini A, Huybrechts I, Inoue M, Islami F, Jakovljevic M, James S, Javanbakht M, Jee SH, Kasaeian A, Kedir MS, Khader YS, Khang YH, Kim D, Leigh J, Linn S, Lunevicius R, El Razek HMA, Malekzadeh R, Malta DC, Marcenes W, Markos D, Melaku YA, Meles KG, Mendoza W, Mengiste DT, Meretoja TJ, Miller TR, Mohammad KA, Mohammadi A, Mohammed S, Moradi-Lakeh M, Nagel G, Nand D, Le Nguyen Q, Nolte S, Ogbo FA, Oladimeji KE, Oren E, Pa M, Park EK, Pereira DM, Plass D, Qorbani M, Radfar A, Rafay A, Rahman M, Rana SM, Søreide K, Satpathy M, Sawhney M, Sepanlou SG, Shaikh MA, She J, Shiue I, Shore HR, Shrime MG, So S, Soneji S, Stathopoulou V, Stroumpoulis K, Sufiyan MB, Sykes BL, Tabarés-Seisdedos R, Tadese F, Tedla BA,
Tessema GA, Thakur JS, Tran BX, Ukwaja KN, Uzochukwu BSC, Vlassov VV, Weiderpass E, Wubshet Terefe M, Yebyo HG, Yimam HH, Yonemoto N, Younis MZ, Yu C, Zaidi Z, Zaki MES, Zenebe ZM, Murray CJL, Naghavi M (2017) Global, Regional, and National Cancer Incidence, Mortality, Years of Life Lost, Years Lived With Disability, and Disability-Adjusted Life-years for 32 Cancer Groups, 1990 to 2015: a systematic analysis for the Global Burden of Disease Study. JAMA Oncol 3: 524-548.

Goto H, Kojima Y, Matsuda K, Kariya R, Taura M, Kuwahara K, Nagai H, Katano H, Okada S (2014) Efficacy of anti-CD47 antibody-mediated phagocytosis with macrophages against primary effusion lymphoma. Eur J Cancer 50(10): 1836-1846.

Gu XB, Tian T, Tian XJ, Zhang XJ (2015) Prognostic significance of neutrophil-to-lymphocyte ratio in non-small cell lung cancer: a metaanalysis. Sci Rep 5: 12493.

Ilie M, Hofman V, Ortholan C, Bonnetaud C, Coelle C, Mouroux J, Hofman P (2012) Predictive clinical outcome of the intratumoral CD66b-positive neutrophil-to-CD8-positive T-cell ratio in patients with resectable nonsmall cell lung cancer. Cancer 118: 1726-1737.

Jaiswal S, Jamieson CH, Pang WW, Park CY, Chao MP, Majeti R, Traver D, Van Rooijen N, Weissman IL (2009) CD47 is upregulated on circulating hematopoietic stem cells and leukemia cells to avoid phagocytosis. Cell 138: $271-285$.

Lagasse E, Weissman IL (1994) bcl-2 inhibits apoptosis of neutrophils but not their engulfment by macrophages. J Exp Med 179: 1047-1052.

Lemaire C, Andr au K, Fraisse CS, Adam A, Souvannavong V (1999) IL-4 inhibits apoptosis and prevents mitochondrial damage without inducing the switch to necrosis observed with caspase inhibitors. Cell Death Differ 6: 813-820.

Liu Y, Buhring HJ, Zen K, Burst SL, Schnell FJ, Williams IR, Parkos CA (2002) Signal regulatory protein (SIRPalpha), a cellular ligand for CD47, regulates neutrophil transmigration. J Biol Chem 277: 10028-10036.

Liu Y, Merlin D, Burst SL, Pochet M, Madara JL, Parkos CA (2001) The role of CD47 in neutrophil transmigration. Increased rate of migration correlates with increased cell surface expression of CD47. J Biol Chem 276: 40156-40166.

Majeti R, Chao MP, Alizadeh AA, Pang WW, Jaiswal S, Gibbs Jr KD, Van Rooijen N, Weissman IL (2009) CD47 is an adverse prognostic factor and therapeutic antibody target on human acute myeloid leukemia stem cells. Cell 138: 286-299.

Marchi LF, Sesti-Costa R, Ignacchiti MD, Chedraoui-Silva S, Mantovani B (2014) In vitro activation of mouse neutrophils by recombinant human interferon-gamma: increased phagocytosis and release of reactive oxygen species and pro-inflammatory cytokines. Int Immunopharmacol 18: $228-235$.

McCracken MN, Cha AC, Weissman IL (2015) Molecular pathways: activating T cells after cancer cell phagocytosis from blockade of CD47 'don't eat me' signals. Clin Cancer Res 21: 3597-3601.

Mora-Jensen H, Jendholm J, Fossum A, Porse B, Borregaard N, TheilgaardMonch K (2011) Technical advance: immunophenotypical characterization of human neutrophil differentiation. J Leukoc Biol 90: 629-634.

Nagahara M, Mimori K, Kataoka A, Ishii H, Tanaka F, Nakagawa T, Sato T, Ono S, Sugihara K, Mori M (2010) Correlated expression of CD47 and SIRPA in bone marrow and in peripheral blood predicts recurrence in breast cancer patients. Clin Cancer Res 16: 4625-4635.

Oldenborg P-A, Gresham HD, Lindberg FP (2001) Cd47-Signal Regulatory Protein $\alpha(\operatorname{Sirp} \alpha)$ Regulates Fc $\gamma$ and Complement Receptor -Mediated Phagocytosis. J Exp Med 193(7): 855-862.

Oldenborg PA (2000) Role of CD47 as a Marker of Self on Red Blood Cells. Science 288(5473): 2051-2054.

Pardoll DM (2012) The blockade of immune checkpoints in cancer immunotherapy. Nat Rev Cancer 12: 252-264.

Peng B, Wang YH, Liu YM, Ma LX (2015) Prognostic significance of the neutrophil to lymphocyte ratio in patients with non-small cell lung cancer: a systemic review and meta-analysis. Int J Clin Exp Med 8: 30983106.

Ratthe C, Ennaciri J, Garces Goncalves DM, Chiasson S, Girard D (2009) Interleukin (IL)-4 induces leukocyte infiltration in vivo by an indirect mechanism. Mediators Inflamm 2009: 193970.

Robb CT, Regan KH, Dorward DA, Rossi AG (2016) Key mechanisms governing resolution of lung inflammation. Semin Immunopathol 38: $425-448$. 
Sanchez-Lara K, Turcott JG, Juarez E, Guevara P, Nunez-Valencia C, Onate-Ocana LF, Flores D, Arrieta O (2012) Association of nutrition parameters including bioelectrical impedance and systemic inflammatory response with quality of life and prognosis in patients with advanced non-small-cell lung cancer: a prospective study. Nutr Cancer 64: $526-534$.

Scheel-Toellner D, Wang K, Craddock R, Webb PR, Mcgettrick HM, Assi LK, Parkes N, Clough LE, Gulbins E, Salmon M, Lord JM (2004) Reactive oxygen species limit neutrophil life span by activating death receptor signaling. Blood 104: 2557-2564.

Serhan CN, Savill J (2005) Resolution of inflammation: the beginning programs the end. Nat Immunol 6: 1191-1197.

Silvestre-Roig C, Hidalgo A, Soehnlein O (2016) Neutrophil heterogeneity: implications for homeostasis and pathogenesis. Blood 127: 2173-2181.

Suzuki K, Hino M, Hato F, Tatsumi N, Kitagawa S (1999) Cytokine-specific activation of distinct mitogen-activated protein kinase subtype cascades in human neutrophils stimulated by granulocyte colony-stimulating factor, granulocyte-macrophage colony-stimulating factor, and tumor necrosis factor-alpha. Blood 93: 341-349.

Suzuki K, Hino M, Kutsuna H, Hato F, Sakamoto C, Takahashi T, Tatsumi N, Kitagawa S (2001) Selective activation of p38 mitogen-activated protein kinase cascade in human neutrophils stimulated by IL-1. J Immunol 167: 5940-5947.

Tak T, Tesselaar K, Pillay J, Borghans JA, Koenderman L (2013) What's your age again? Determination of human neutrophil half-lives revisited. $J$ Leukoc Biol 94: 595-601.

Tanoglu A, Yiyit N, Berber U, Karagoz E (2014) Is the combination of neutrophil to lymphocyte and platelet to lymphocyte ratios a useful predictor of treatment response and prognosis in patients with non-small cell lung cancer? Asian Pac J Cancer Prev 15: 4373-4373.

Tecchio C, Scapini P, Pizzolo G, Cassatella MA (2013) On the cytokines produced by human neutrophils in tumors. Semin Cancer Biol 23: 159170.

Todaro M, Lombardo Y, Francipane MG, Alea MP, Cammareri P, Iovino F, Di Stefano AB, Di Bernardo C, Agrusa A, Condorelli G, Walczak H, Stassi G (2008) Apoptosis resistance in epithelial tumors is mediated by tumor-cell-derived interleukin-4. Cell Death Differ 15: 762-772.

Tomita M, Shimizu T, Ayabe T, Nakamura K, Onitsuka T (2012) Elevated preoperative inflammatory markers based on neutrophil-to-lymphocyte ratio and C-reactive protein predict poor survival in resected non-small cell lung cancer. Anticancer Res 32: 3535-3538.

Weiner LM, Surana R, Wang S (2010) Monoclonal antibodies: versatile platforms for cancer immunotherapy. Nat Rev Immunol 10: 317-327.

Woytschak J, Keller N, Krieg C, Impellizzieri D, Thompson RW, Wynn TA, Zinkernagel AS, Boyman O (2016) Type 2 interleukin-4 receptor signaling in neutrophils antagonizes their expansion and migration during infection and inflammation. Immunity 45: 172-184.

Yao Y, Yuan D, Liu H, Gu X, Song Y (2013) Pretreatment neutrophil to lymphocyte ratio is associated with response to therapy and prognosis of advanced non-small cell lung cancer patients treated with first-line platinum-based chemotherapy. Cancer Immunol Immunother 62: 471-479.

Yin Y, Wang J, Wang X, Gu L, Pei H, Kuai S, Zhang Y, Shang Z (2015) Prognostic value of the neutrophil to lymphocyte ratio in lung cancer: a meta-analysis. Clinics (Sao Paulo) 70: 524-530.

Yoshida K, Tsujimoto H, Matsumura K, Kinoshita M, Takahata R, Matsumoto Y, Hiraki S, Ono S, Seki S, Yamamoto J, Hase K (2015) CD47 is an adverse prognostic factor and a therapeutic target in gastric cancer. Cancer Med 4: 1322-1333.

Zhang H, Zhang L, Zhu K, Shi B, Yin Y, Zhu J, Yue D, Zhang B, Wang C (2015) Prognostic significance of combination of preoperative platelet count and neutrophil-lymphocyte ratio (COP-NLR) in patients with non-small cell lung cancer: based on a large cohort study. PLOS ONE 10: e0126496.

Zhao H, Wang J, Kong X, Li E, Liu Y, Du X, Kang Z, Tang Y, Kuang Y, Yang Z, Zhou Y, Wang Q (2016) CD47 promotes tumor invasion and metastasis in non-small cell lung cancer. Sci Rep 6: 29719.

Zhao XW, Van Beek EM, Schornagel K, Van Der Maaden H, Van Houdt M, Otten MA, Finetti P, Van Egmond M, Matozaki T, Kraal G, Birnbaum D, Van Elsas A, Kuijpers TW, Bertucci F, Van Den Berg TK (2011) CD47-signal regulatory protein-alpha (SIRPalpha) interactions form a barrier for antibody-mediated tumor cell destruction. Proc Natl Acad Sci USA 108: 18342-18347.

This work is published under the standard license to publish agreement. After 12 months the work will become freely available and the license terms will switch to a Creative Commons AttributionNonCommercial-Share Alike 4.0 Unported License.

Supplementary Information accompanies this paper on British Journal of Cancer website (http://www.nature.com/bjc) 